\title{
FLEXURAL RESISTANCE OF MASONRY WALL RETROFITTED WITH TIMBER PANEL UNDER OUT-OF-PLANE LOADING
}

\author{
ORNELLA IUORIO ${ }^{*}{ }^{*}$, JAMIU A. DAUDA ${ }^{1}$ AND PAULO B. LOURENCO ${ }^{2}$ \\ ${ }^{1}$ School of Civil Engineering \\ University of Leeds \\ Woodhouse Lane, LS2 9JT, Leeds, UK \\ e-mail: o.iuorio@leeds.ac.uk (*corresponding author) \\ cnjad@leeds.ac.uk \\ ${ }^{2}$ Department of Civil Engineering \\ University of Minho \\ Azurém, P-4800-058 Guimarães, Portugal \\ e-mail:pbl@civil.uminho.pt
}

Keywords: Flexure, OSB, Retrofit, Sustainable, URM

\begin{abstract}
Retrofit of unreinforced masonry (URM) structures is incessantly attracting interests of masonry professionals. Because there are enormous URM structure stocks in different parts of the world that have shown vulnerability to damage against out-of-plane actions due to having limited flexural strength and deformation capacity [1]. As such, there is a global trend of promoting the development of sustainable retrofit techniques for URM structures. The authors' previous study [2] has introduced the application of oriented strand board type $3(O S B / 3)$ as a prospective sustainable retrofit material for URM wall with evidence of improving the flexural performances. This paper presents, for the first time,experimental works on $1115 \times 1115 \times 215 \mathrm{~mm}$ double wythe single leaf URM walls. Specifically, quasi-static out-of-plane loading tests were carried out on two plain specimens, two single-sided retrofitted walls and two double-sided retrofitted walls. The flexural and displacement capacities were evaluated in both plain and retrofitted specimens, and the results substantiated that OSB/3 application improves the flexural capacity of masonry wall. Therefore, the application of OSB $/ 3$ for retrofitting URM buildings can be considered as an inexpensive, efficient and sustainable retrofit technique.
\end{abstract}

\section{INTRODUCTION}

Unreiforced masonry structures are among the oldiest type of constructions, and has seen usage worldwide. However, masonry is a complex construction material and the assessment of its structural response and mechanical properties is a challenge [3]. Its behaviour is often influenced by the quality of materials used, workmanship, and the bond pattern [4]. It is quasi-brittle in nature, hefty in self-weight, contains loose components, has low tolerances to oscillation and thus undergoes sudden brittle failure without much warning to the occupants [ $1 \&$ 5]. Therefore, in case of sudden failure under out-of-plane loading, occupants of URM 
structures do not have enough time to run for safety. Hence, detail consideration for retrofit of old URM structures is highly encouraged to ensure that they can perform their highly sought energy absorption and force relieving roles against failures.

The failure of URM wall is mainly against horizontal forces resulting in flexure due to outof-plane bending and in shear due to in-plane bending [6 \& 7]. URM walls have considerable compressive strength under vertical loading, but they are relatively weak in tensile strength to resist lateral (out-of-plane) loads. They are weak against overpressure from blast effect induced by explosion or earthquake, snow-avalanche for habitation in a mountain area, extreme wind, and mostly lateral (out-of-plane) loading. Specifically, the work presented in this paper aims to improve the out-of-plane capacity of URM walls against out-of-plane loading.

Previously, the authors have introduced the application of oriented strand board (OSB) type 3 to retrofit URM walls to increase their structural capacity and flexural resistance $[2,8]$. Before the application of the proposed retrofit scheme, an understanding of the mechanical properties of the constituents (i.e. solid fired clay brick and cement-lime mortar) that were used to construct the masonry walls for investigating the efficiency of the proposed retrofit technique was carried out and reported $[9,10]$. After that, small-scale test on $215 \times 102.5 \mathrm{x}$ $665 \mathrm{~mm}$ masonry prisms in the form of four-point bending test was performed to determine the out-of-plane flexural strength [2]. The flexural bond strength test was carried out to provide a simplified means of gathering data on the flexural strength of plain URM prisms and URM prisms retrofitted with $18 \mathrm{~mm}$ thick OSB timber panel and the two selected connection types. The ter and the connection bet The test provided an behaviour of masonry prisms. Thus, it is a pedestal for the d larger-scale tests described in this paper and to validate
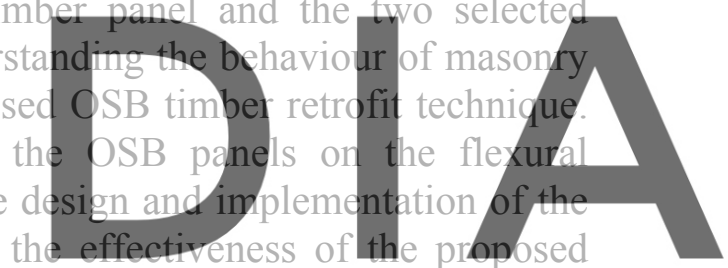
retrofit technique.

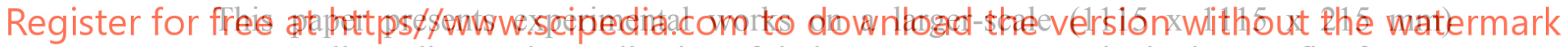
masonry walls to discuss the application of timber-masonry composite in the retrofit of URM walls. The overall experimental program for investigating the proposed techniques includes the first two stages of work that has been described in $[2,9 \& 10]$. Here, an experimental program involving subjecting both plain and timber retrofitted URM walls to out-of-plane loading using quasi-static (monotonic) loading scheme is presented. The results of the experimental works are also presented and analysed to evaluate the performance of the proposed OSB retrofit techniques of URM walls.

In addition to the introductory information in section 1, this paper entails four other sections, including section 2 for the material properties, section 3 for the test program and test setup. Afterwards, the results of the experimental works were presented and analysed in section 4 . The paper ends with conclusions and recommendations in section 5.

\section{MATERIALS}

The full experimental characterisation of mechanical properties of masonry components (i.e. UK fired solid clay bricks and mortar) has been presented in $[9,10]$. The reasons for selecting each material used in this study have also been highlighted in the referenced paper 
$[9,10]$. However, the most significant properties, brick strength and water absorption for the brick unit and consistency value and compressive strength of mortar are reported hereafter.

\subsection{Masonry Components (Brick Unit and Mortar)}

The Masonry test specimens were built using an engineering class B fired solid clay bricks with UK standard size $215 \times 102.5 \times 65 \mathrm{~mm}$ (length $\mathrm{x}$ thickness $\mathrm{x}$ height). The brick unit has an average strength of $88 \mathrm{~N} / \mathrm{mm}^{2}$ (CoV of $2 \%$ ) and $4 \%$ water absorption (CoV of $5 \%$ ). The unit strength affects the behaviour of the specimens under loading, and the water absorption is important for the bond between the brick and mortar. If the brick water absorption is too high, the mortar dries up quickly causing dry shrinkage in the mortar, and if the bricks absorb more water than recommended it reduces the strength and durability of the specimen. For these reasons, it is important to clarify these two significant properties (brick strength and water absorption).

The mortar used for the construction of all specimens is type N (general purpose) mortar mix with a ratio of 1:1:6 (Type II Cement: aerial lime: sand) by volume. The mix ratio gives an average dropping value of $10.2 \mathrm{~mm}$ and average cube strength of $7.1 \mathrm{~N} / \mathrm{mm}^{2}$ at 28 days. For conformity, the mortar was sampled during the construction of all specimens and gave comparable results.

\subsection{Retrofit Material (Oriented Strand Board and Commections)}

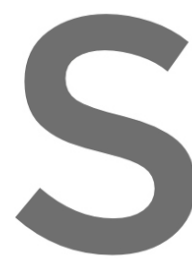

\section{For the retrofit materials,} selected for this study. of $0.3 \mathrm{~N} / \mathrm{mm}^{2}$, and $\mathrm{moc}$ major and minor axi The adhesive anchor connection
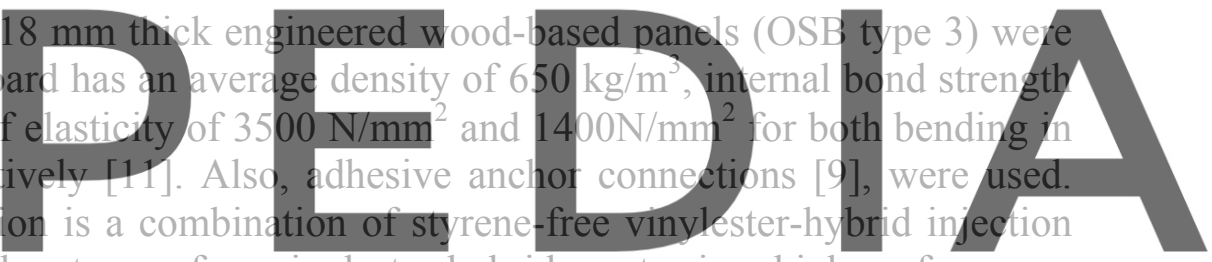
mortar and A4 anchor rod. The styrene-free vinylester-hybrid mortar is a high-performance

\section{METHODS}

\subsection{Test Program}

Six 1115 x 1115 x 215 mm single leaf, double wythe solid URM walls were tested in the laboratory under four-point bending test using quasi-static monotonic loading scheme. The experimental campaign (Table 1) involved testing: (a) two samples as plain wall (PW1115) to serve as reference to measure the effectiveness of the proposed retrofit techniques, (b) two samples each retrofitted with $18 \mathrm{~mm}$ thick OSB using adhesive anchor connections on the face in tension (1SRW1115) and, (c) two samples each on both sides of the wall (2SRW1115). The specimens were labelled as follows (table 1):

PW stands for Plain masonry Wall

1SRW stands for Wall Retrofitted with OSB panel on one Side

2SRW stands for wall Retrofitted with OSB panel on two Sides

1115 indicates the wall height,

Suffix number (1 or 2) represents the unique specimen ID. 
Table 1: Test program specimen identification

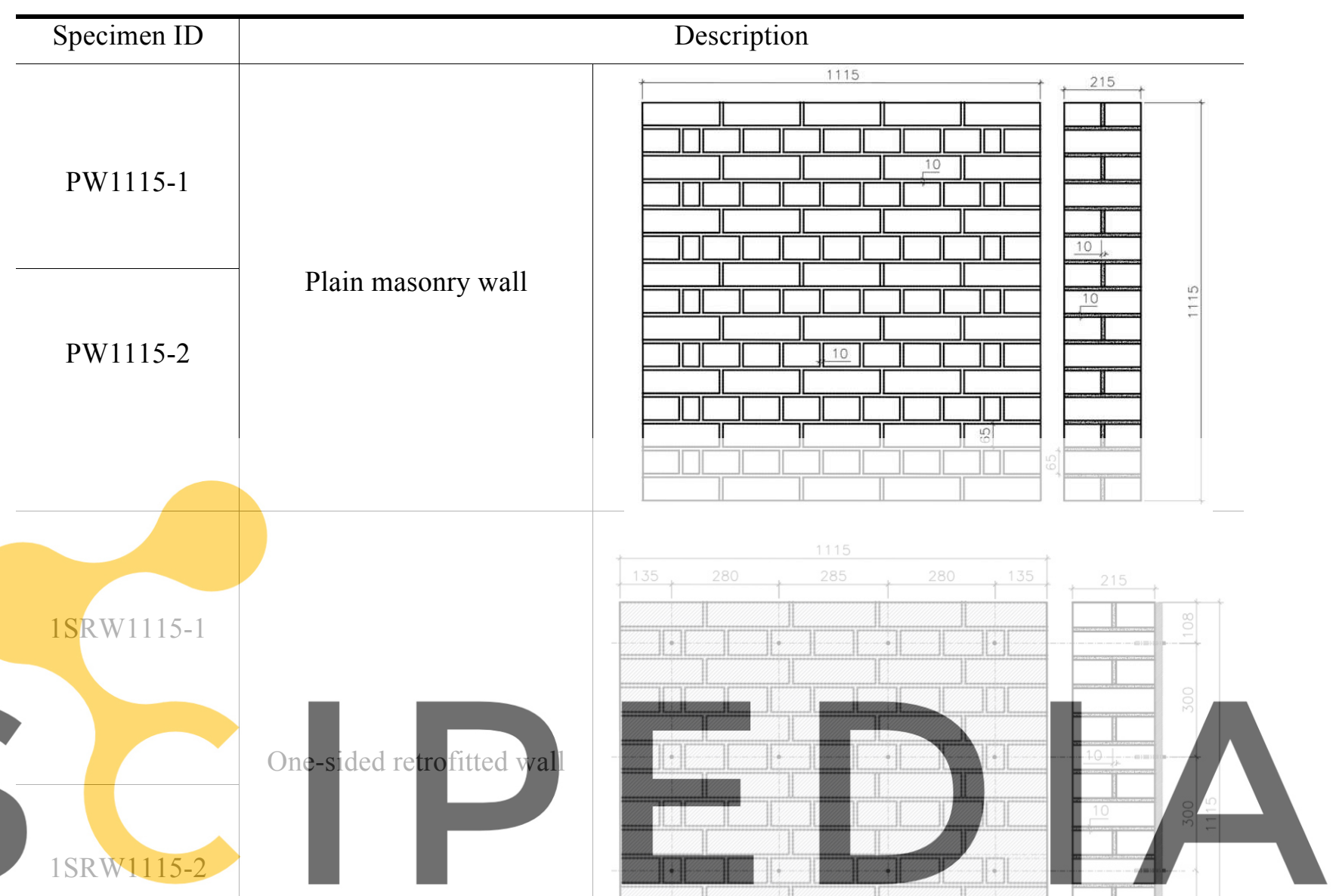

Register for free at https//www.scipedia.com to download the version without the watermark

2SRW1115-1 Two-sided retrofitted wall




\subsection{Test Setup}

The specimens were tested under four-point loading test arrangement [12] to assess their flexural behaviour. The test was load controlled, and the load was applied to each tested specimen using a hydraulic ram and was distributed through a steel spreader arrangement in the central area of the wall (Fig. 1). All specimens were tested with simply supported boundary condition and a vertical pre-compression load $(305 \times 305 \times 240$ UC section amounting to $3 \mathrm{kN}$ load) on top of the wall. The specimen constructed on reinforced concrete footing was rested on $50 \mathrm{~mm}$ diameter cylindrical roller with the axis of the roller parallel to the face of the specimen. At the back of the wall, $5 \mathrm{~mm}$ thick metal plate was fixed across the middle of the top and bottom course of the wall to provide contacts for the simply supports. Similarly, $5 \mathrm{~mm}$ thick metal plate was fixed at $1 / 4$ th and $3 / 4$ th of the specimen height at the front side to provide contacts for which the loading rollers rest.

The loading scheme was such that an initial load was applied continuously at a rate of $1 \mathrm{kN} / \mathrm{min}$ for up to $5 \mathrm{kN}$ and then maintained for 5 mins period. The purpose of maintaining the applied load was to allow the wall assembly to come to substantial rest before taking the next set of reading [11]. Also, this helped to observe any time-dependent deformation and load redistribution. The load steps were repeated continuously for $10 \mathrm{kN}, 15 \mathrm{kN}, 20 \mathrm{kN}, 25 \mathrm{kN}$, and $30 \mathrm{kN}$ load and maintained for $5 \mathrm{mins}$ period at each load step. After that, the load was increased continuously to the failure of the specimens. In order to obtain the maximum capacity of the retrofitted walls, the applied load was increased continually after the first crack

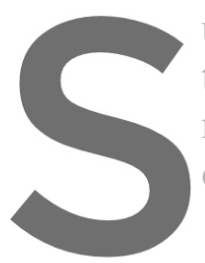
until additional cracks the back of the masonry monitored using a $200 \mathrm{KN}$ capacity ring load deflections of the test specimen along the wall cr
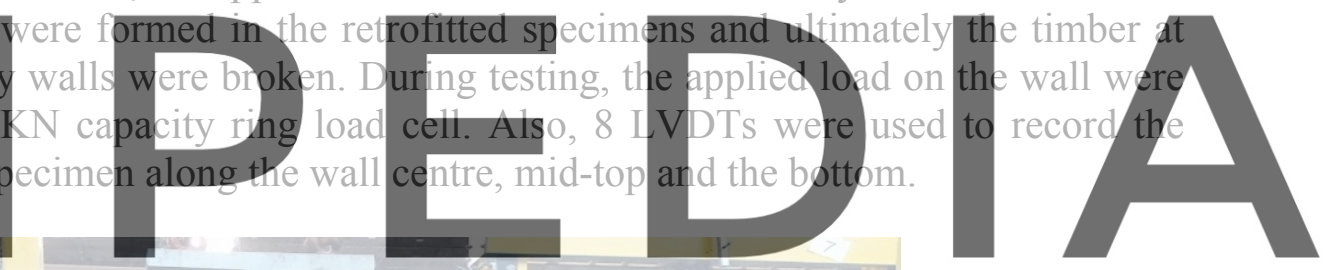

Register for free at https//www.scipedia.com to download the version without the watermark

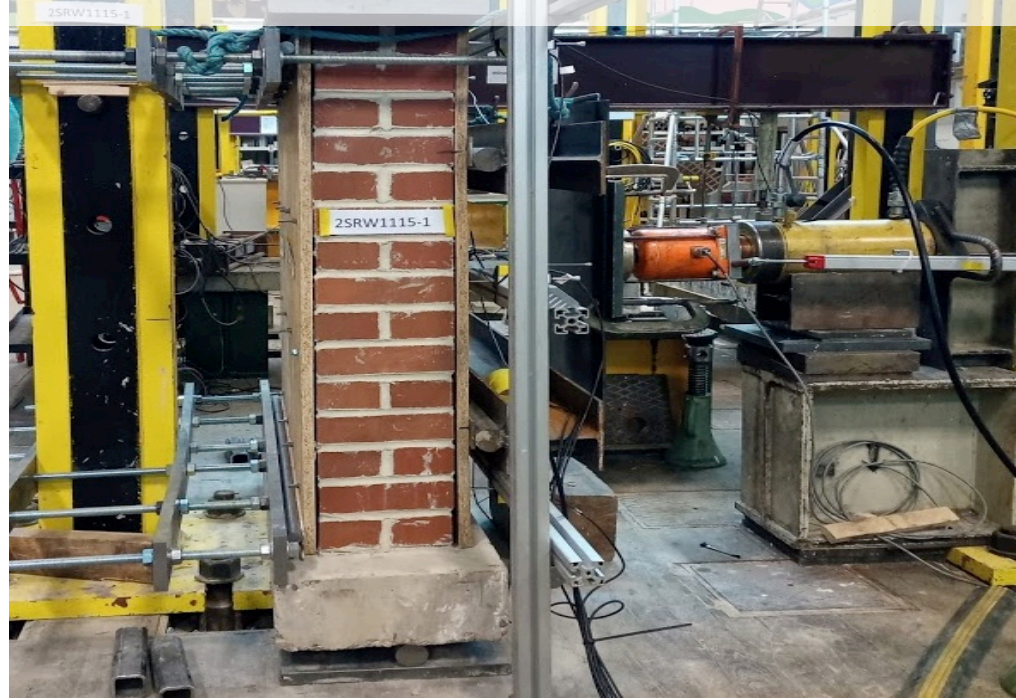

Figure 1: Test set up 


\section{TEST RESULT}

\subsection{Load-Displacement Curve}

The net out of plane displacement in the mid-height of the wall was estimated by deducting the mean displacement recorded at the top and bottom of the specimens from the average midheight displacement. This deduction accounted for the unexpected displacement at the top and bottom of the wall. Figure 2 shows the load-displacement curves obtained from the experiment. The inference from figure 2 shows that the plain specimens PW1115-1 \& PW1115-2 have a quasi-linear behaviour up to about $15000 \mathrm{~N}$ loads, which corresponds to the onset of crack formation in the plain wall. After that, the load continuously increased with small increments in the out-of-plane displacement before the specimen failed. At the failure point, the displacement suddenly increased. This increment is due to the brittle nature of the failure pattern. The maximum load attained by PW1115-1 and PW1115-2 is $38330 \mathrm{~N}$ and $39720 \mathrm{~N}$ respectively. The average of these two value (39025 N) was chosen as a baseline to evaluate the effectiveness of the proposed timber-retrofit technique in both single-sided and double-sided retrofitted walls. For the retrofitted wall specimens, the first crack appeared at an average load of $52750 \mathrm{~N}$ and $68714 \mathrm{~N}$ for 1SRW1115 and 2SRW1115 respectively. Finally, the average peak load and out-of-plane displacement at the specimens mid-height were estimated as (114622 N, $25.88 \mathrm{~mm})$ and $(120559 \mathrm{~N}, 12.61 \mathrm{~mm})$ for 1SRW1115 and 2SRW1115, respectively. Figure 2 reveals that the proposed retrofit technique has

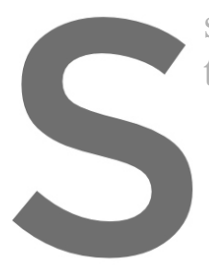
substantially increased

\section{times when compared. to}
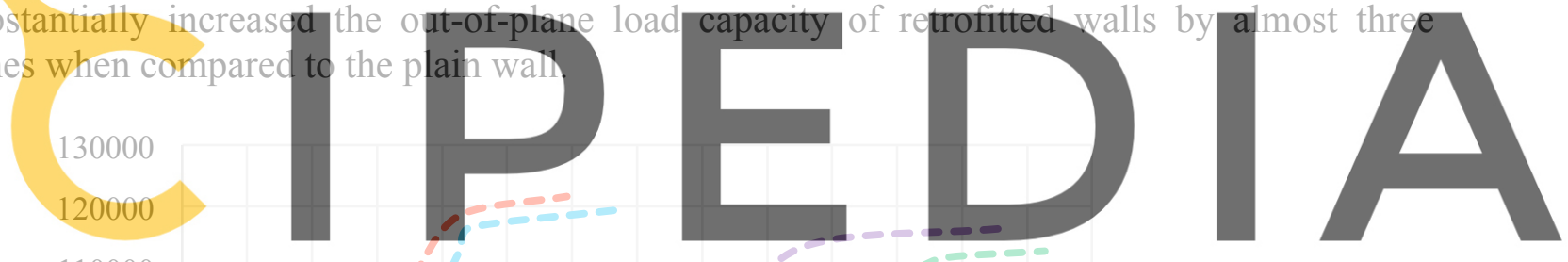

Register for freø0atohttps//www.scipedia.com to download the version without the watermark

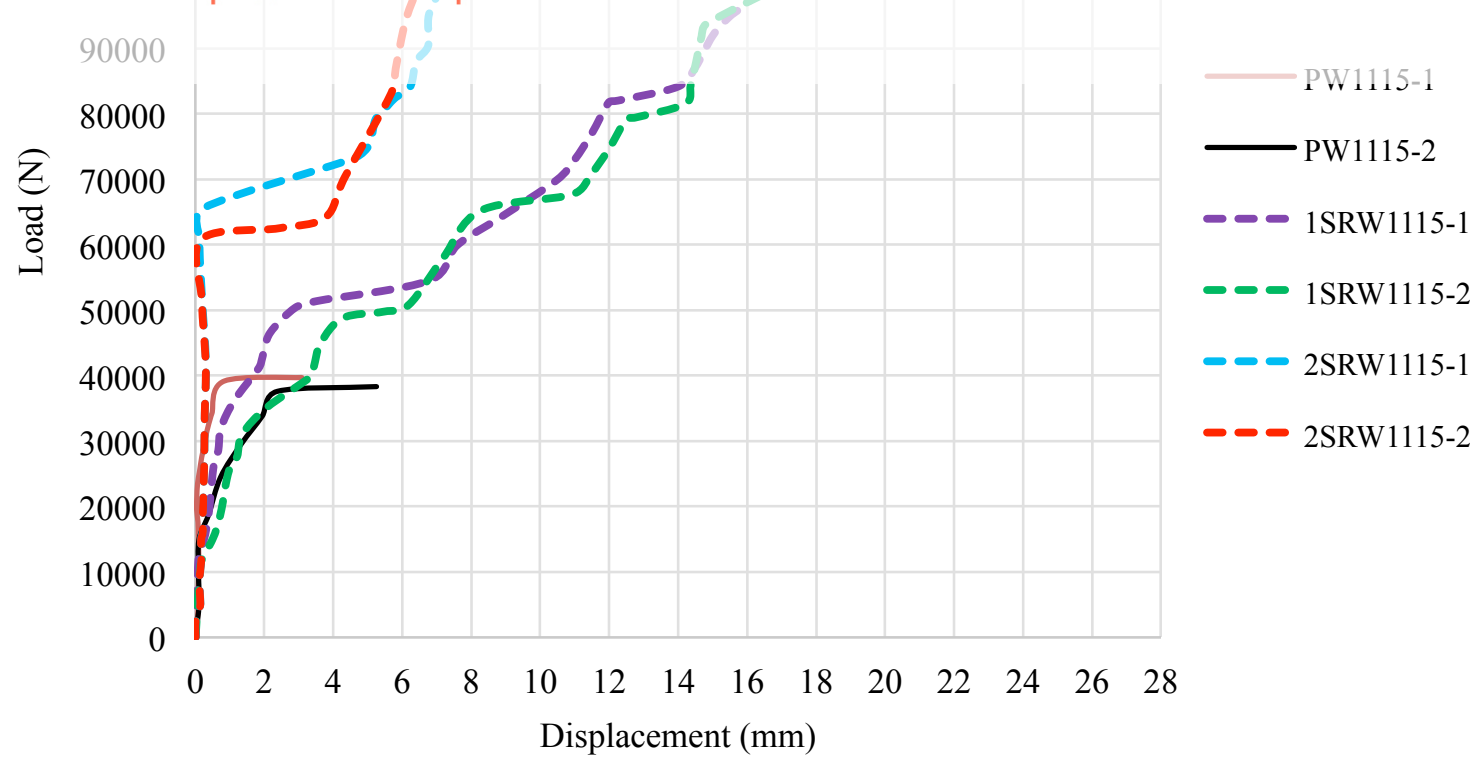

Figure 2: Load vs Displacement curve for specimens 


\subsection{Failure Pattern}

The observed failure pattern in the plain walls is characterised by the sudden formation and rapid opening of the crack in the unit/mortar joint interface throughout the whole wall specimen thickness. The failure of the plain masonry wall is quasi-brittle and always started with the formation of a crack opening in one bed joint at the tensile face of the specimen (i.e. the side opposing the loading face). Subsequently, the crack occurred in the bed joint was propagated through the perpend joint to the next bed joint. The crack occurred throughout the whole thickness of the wall so that the unit-mortar interface was completely separated (Fig 3).

The behaviour of single-sided retrofitted masonry wall (1SRW) shows that the net out-ofplane displacement of the specimens increased with the applied out-of-plane load from the beginning. This behaviour indicates that 1SRW specimens started to deflect while remaining undamaged. The failure of 1SRW began from the tensile face with the first crack occurred in the unit-mortar interface at $54600 \mathrm{~N}$ and $50900 \mathrm{~N}$ for 1SRW1115-1 and 1SRW1115-2 respectively. But the application of the OSB timber panel at the back of the wall specimens kept the specimens un-separated after the first crack. Therefore the loading increased continuously until other cracks appeared in the bed joints parallel to the first crack still within the inner bearing for 1 SRW and 2SRW (Fig. 3b \& 3c).

Meanwhile, the double-sided retrofitted wall (2SRW) shows approximately no displacement $(0.25 \mathrm{~mm})$ before the first crack occurred in the masonry part at an average load of $68714 \mathrm{~N}$. This implies that the addition of the timber panel on the compression face (i.e.

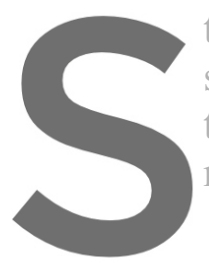
the face where the load specimens. So, double-s the first crack occurre respectively.
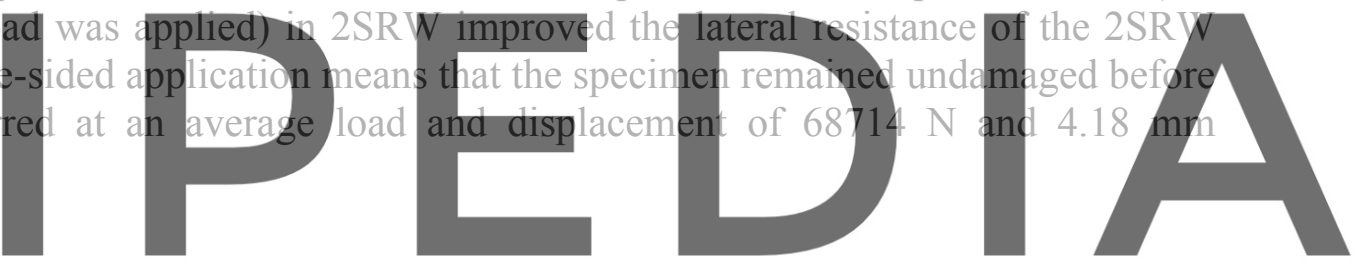

Register for free at https//www.scipedia.com to download the version without the watermark 

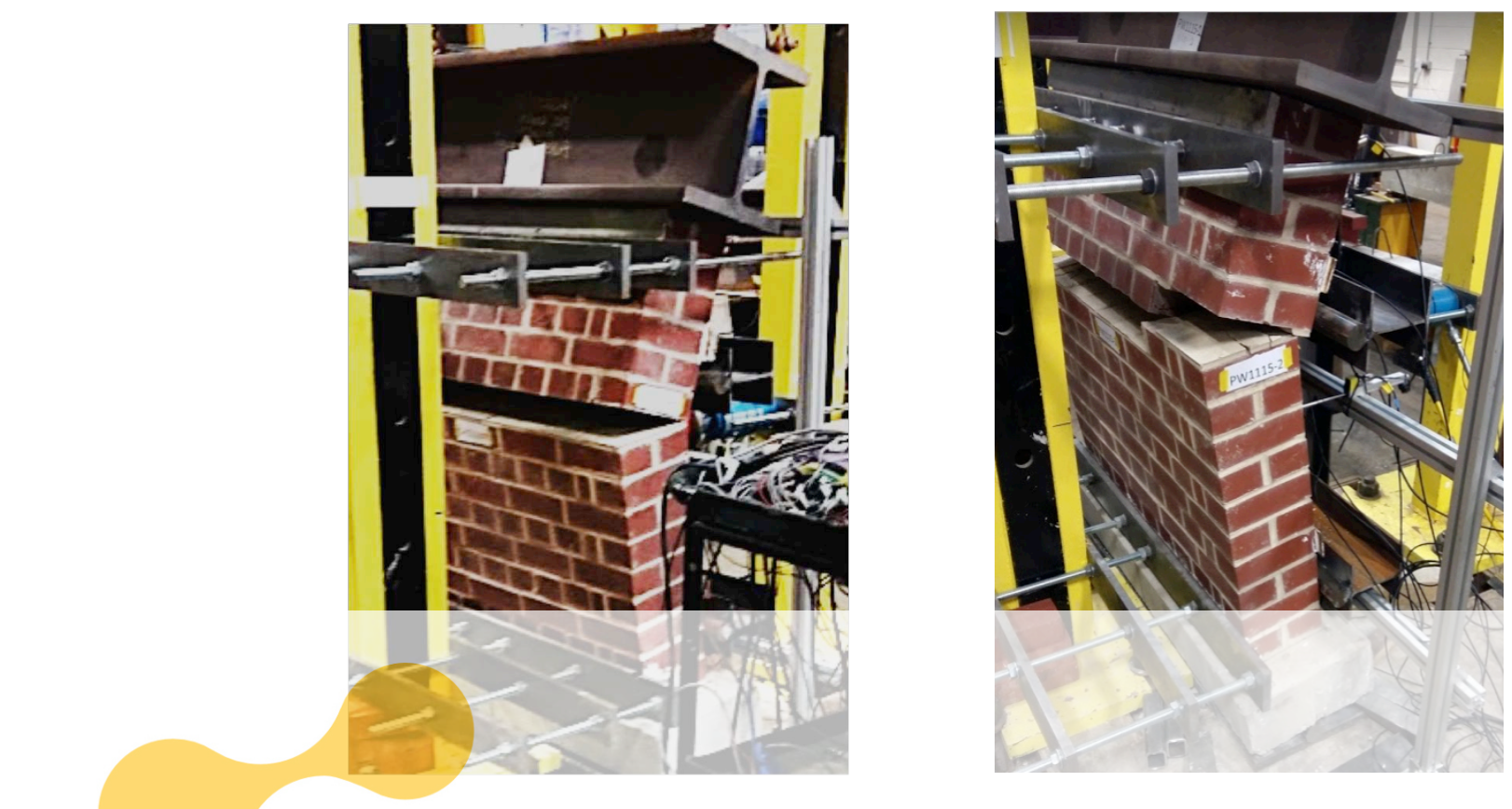

a)

PW1115-1

PW1115-2
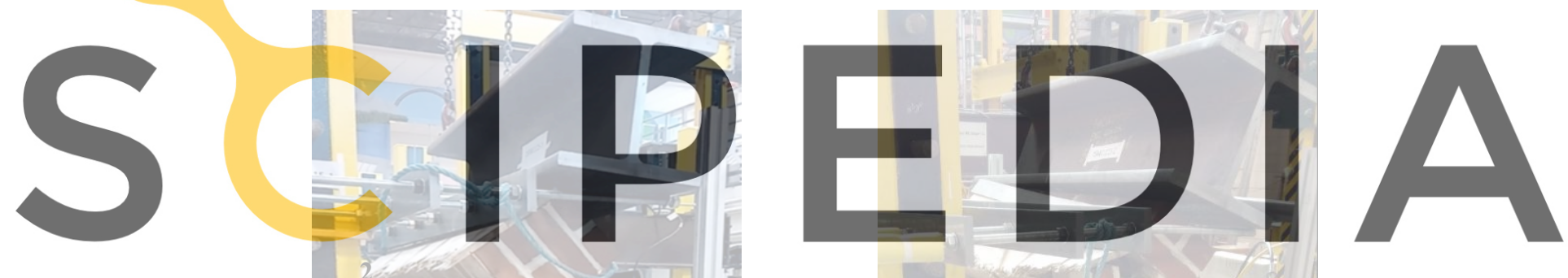

Register for free at https//www.scipedia.com to download the version without the watermark
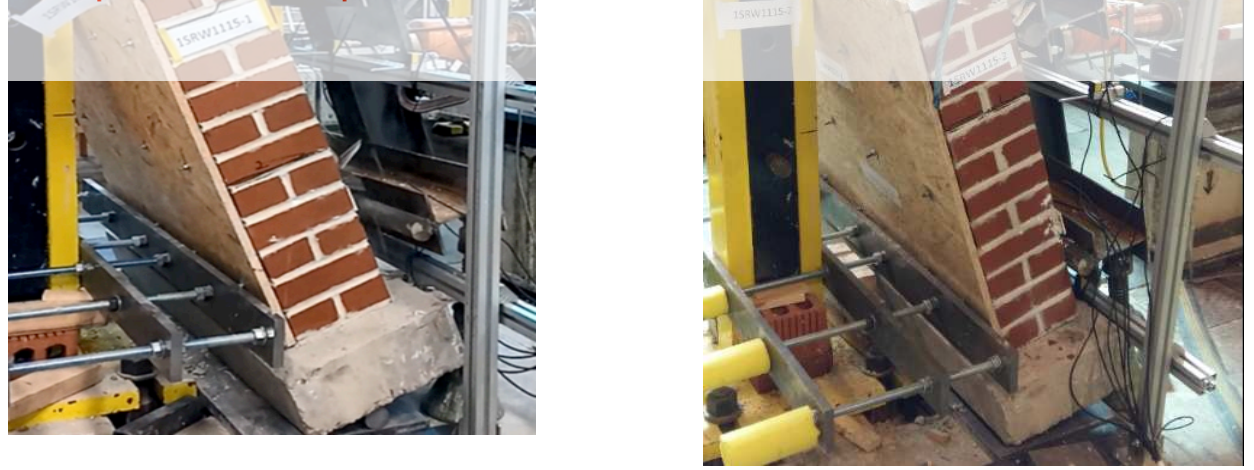

b)

1SRW1115-1

1SRW1115-2 

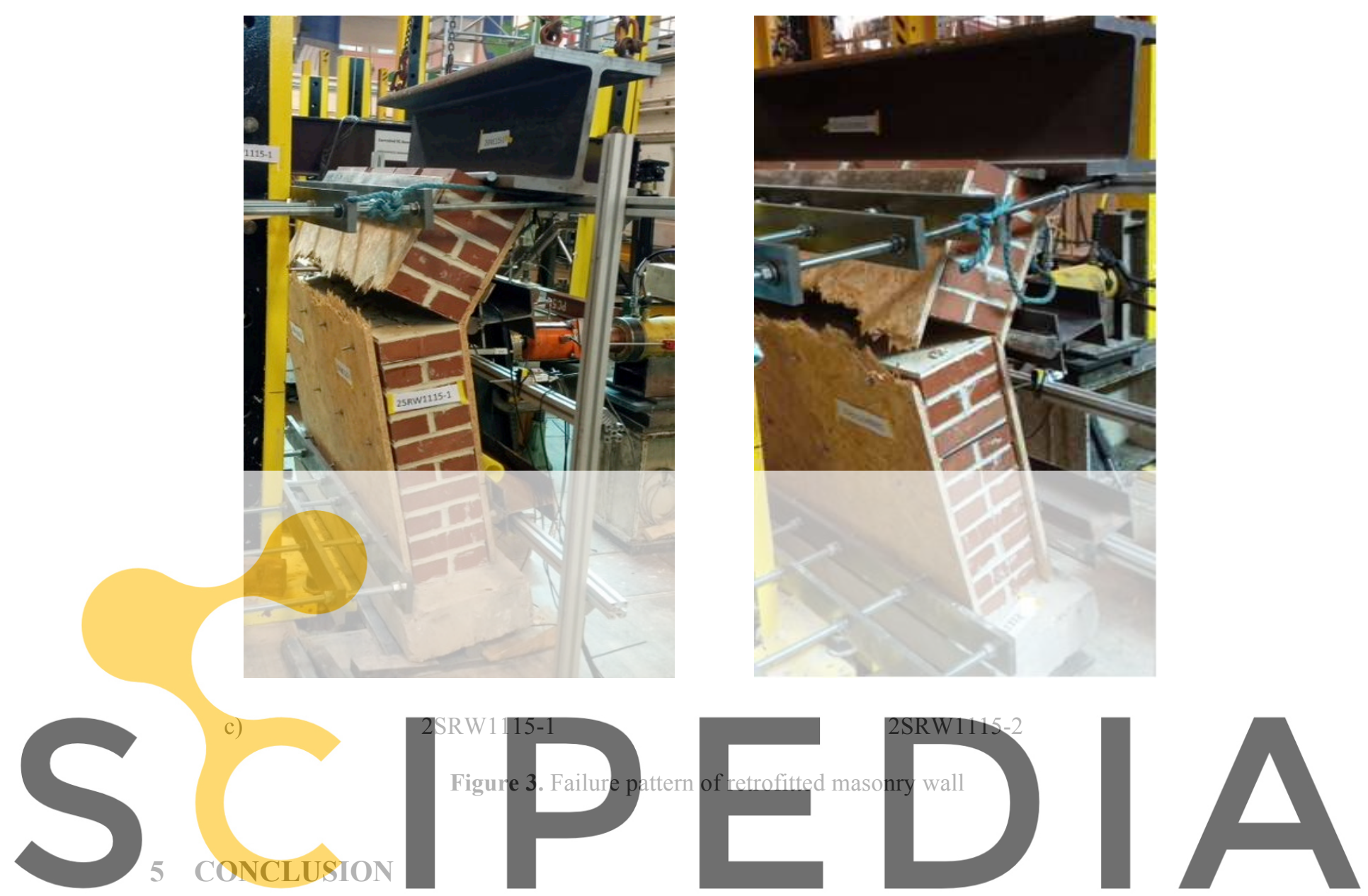

This paper has presented a larger-scale experimental study to propose the application of

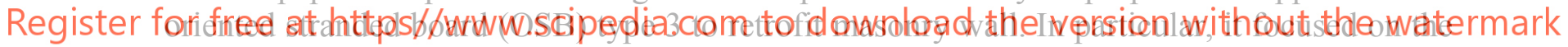
effectiveness of the proposed timber-based retrofit technique against out-of-plane failure. Here, six tests have been performed on 1115 x 1115 x $215 \mathrm{~mm}$ single leaf, double wy the solid masonry walls. Two of the walls were tested as plain wall (PW), two as single-sided retrofitted masonry wall (1SRW), and the last two as double-sided retrofitted masonry wall (2SRW).

Out-of-plane bending test in the form of four-point loading test was performed on all the six specimens. The aim was to obtain the response of both the plain and retrofitted masonry walls against out-of-plane loading to evaluate the performance of the proposed technique. The aim was achieved by assessing the load-carrying capacities and displacement capacities of both plain and retrofitted walls.

The main conclusion from this study is that oriented strand board (OSB) type 3 can considerably increase the flexural capacity of masonry walls when subjected to out-of-plane loading. An astonishing increase of about 300\% load capacity can be achieved in a double wythe masonry wall and can be up to about $500 \%$ increase in a more weaker wall such as single leaf masonry wall as previously demonstrated in the earlier study [2].

A limitation of this study is that the results and observations are based on specimens with free boundary conditions that replicate masonry walls without returning walls at the corner, 
which is a rarity. However, many experimental works in literature $[6,7,12]$ have shown that tests on panels without corners are a good indication in assessing the out-of-plane capacity of URM wall. Hence, in the future, an extension of this study would be beneficial to investigate the performance of the proposed technique on typical load-bearing walls together with corner walls.

\section{REFERENCES}

[1] Lourenço P., Mendes N., Costa A., and Campos-Cost A. Methods and Challenges on the Out-of-Plane Assessment of Existing Masonry Buildings. International Journal of Architectural Heritage, 11(1) pp.1.

[2] Dauda J., Iuorio O., and Lourenço P. (2019). Experimental Study of Out-of-Plane Behavior of Timber Retrofitted Masonry Prisms. In P.B.Dillon \& F.S.Fonseca (Eds.), Proceedings of the Thirteenth North American Masonry Conference, Salt Lake City, Utah (pp. 1100-1109).

[3] Costa, A., Arêde, A., Costa, A. and Oliveira, C. (2011). Out-of-plane Behaviour of Existing Stone Masonry Buildings: Experimental Evaluation. Bulletin of Earthquake Engineering, 10(1), pp.93-111.

[4] Wang, C., Forth, J., Nikitas, N. and Sarhosis, V. (2017). Retrofitting Of Masonry Walls By Using a Mortar Joint Technique: Experiments And Numerical Validation. Engineering

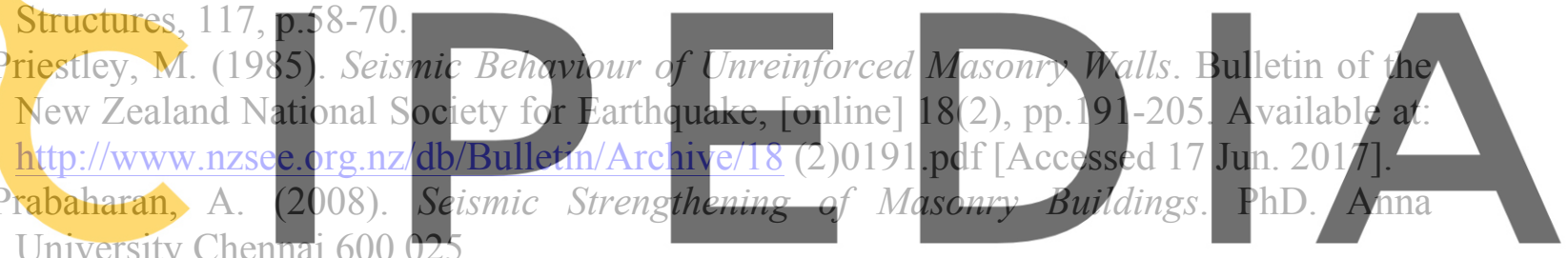

University Chentail 600025.
[7] Nazir, S. (2015). Studies on the Failure of Unreinforced Masonry Shear Walls. PhD.

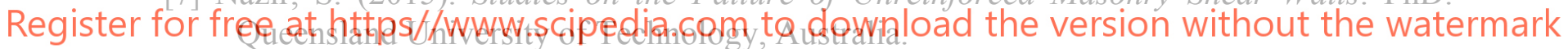

[8] Dauda J. and Iuorio O. (2019). Timber-Masonry Composite Systems for Retrofit of Unreinforced Masonry Wall. In Proceedings of 2019 Society for Earthquake and Civil Engineering Dynamics Conference (SECED), London September 2019.

[9] Dauda J., Iuorio O. and Lourenço P. (2020). Numerical Analysis and Experimental Characterization of Brick Masonry. International Journal of Masonry Research and Innovation, Vol. 5 Issue: 3, pp.321-347, DOI: 10.1504/IJMRI.2020.10028163.

[10] Dauda J., Iuorio, O. and Lourenco P. (2018). Characterization of Brick Masonry: Study towards Retrofitting URM Walls with Timber-Panels. In: 10th International Masonry Conference (10thIMC). In proceedings of 10th International Masonry Conference (10thIMC), 09-11 Jul 2018, Milan, Italy.

[11] Anon, A. (2018). Technical Information Sheet for Oriented Strand Board. [online] Available at: http://www.osb-info.org/Assets/file/EN/OSB_Technical_Information [Accessed 23 Jul. 2018].

[12] ASTM E72 - 15 (2015). Standard Test Methods of Conducting Strength Tests of Panels for Building Construction. West Conshohocken, PA: ASTM International. 